\title{
"T. T." AND "MR. W. H."
}

T. T. (THOMAS THORPE) published the Sonnets in 1609 , naming W. H. (identity unknown) as their "onlie begetter." Of Thorpe's publishing venture, the most favorable judgment we can make is that no one, least of all Shakespeare, appears to have authorized it. As for W. H.'s role, we can only guess whether he "begot" the Sonnets by inspiring them or by procuring them in manuscript for Thorpe's use. Beyond these uncertainties are the chances that Thorpe was guilty of piracy, W. H. of something close to theft.

Yet in raising these questions we sometimes forget to ask another: had it not been for T. T. and W. H., would there be any text of the Sonnets? 
